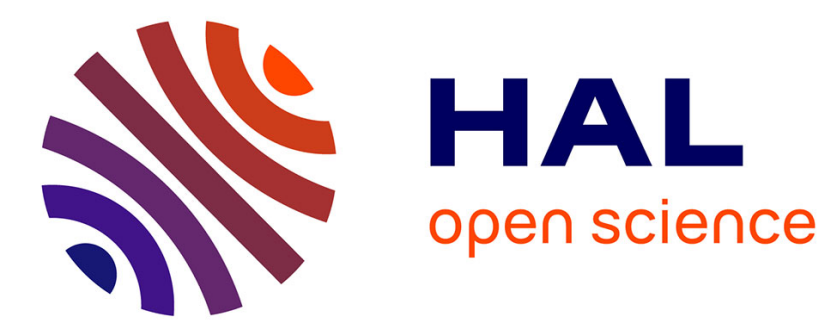

\title{
Breast cancer risk in women who fulfill high-risk criteria: at what age should surveillance start?
}

Andreas Brandt, Justo Lorenzo Bermejo, Jan Sundquist, Kari Hemminki

\section{To cite this version:}

Andreas Brandt, Justo Lorenzo Bermejo, Jan Sundquist, Kari Hemminki. Breast cancer risk in women who fulfill high-risk criteria: at what age should surveillance start?. Breast Cancer Research and Treatment, 2009, 121 (1), pp.133-141. 10.1007/s10549-009-0486-y . hal-00485064

\section{HAL Id: hal-00485064 https://hal.science/hal-00485064}

Submitted on 20 May 2010

HAL is a multi-disciplinary open access archive for the deposit and dissemination of scientific research documents, whether they are published or not. The documents may come from teaching and research institutions in France or abroad, or from public or private research centers.
L'archive ouverte pluridisciplinaire HAL, est destinée au dépôt et à la diffusion de documents scientifiques de niveau recherche, publiés ou non, émanant des établissements d'enseignement et de recherche français ou étrangers, des laboratoires publics ou privés. 
1 Breast cancer risk in women that fulfill high risk criteria: at what age should surveillance

2 start?

3

4 Andreas Brandt ${ }^{1}$, Justo Lorenzo Bermejo ${ }^{1}$, Jan Sundquist ${ }^{2,3}$ and Kari Hemminki ${ }^{1,2}$ 5

$6 \quad{ }^{1}$ Division of Molecular Genetic Epidemiology, German Cancer Research Centre (DKFZ), 769120 Heidelberg, Germany;

$8 \quad{ }^{2}$ Center for Primary Care Research, Lund University, 20502 Malmö, Sweden;

$9{ }^{3}$ Stanford Prevention Research Center, Stanford University School of Medicine, California, 10 USA

11

12 Word count: 250 abstract, 3150 text

15 Keywords: breast cancer; hereditary breast cancer; familial breast cancer; age of onset;

16 clinical risk criteria

17

18

19

$20 *$ Correspondence to: Andreas Brandt, Division of Molecular Genetic Epidemiology, German

21 Cancer Research Centre (DKFZ), Im Neuenheimer Feld 580, D-69120 Heidelberg, Germany.

22 Tel: +49-6221-421805; Fax: +49-6221-421810; E-Mail: andreas.brandt@ dkfz.de 


\section{Abstract}

Family history is a strong predictor of hereditary breast cancer, particularly when it includes cases of early onset or bilateral breast cancers and multiple cases of breast or ovarian cancers. This article provides relative risks and cumulative risks of breast cancer of women whose family history indicates high risk. Specifically, the aim was to determine how many years earlier the high risk women reach the cumulative risk of women without family history at the age at which screening in average risk women is initiated.

The women of the nation-wide Swedish Family-Cancer Database were classified according to clinical criteria based on family history suggesting high risk for hereditary breast ovarian cancer syndrome. The relative risks of breast cancer were calculated as hazard ratio using Cox regression. Cumulative risks of breast cancer were estimated with a stratified Cox model based on Tsiatis' method.

\section{The hazard ratios of breast cancer for the considered criteria ranged from 1.50 to 5.99. The} cumulative risks ranged from $1-10 \%$ by age 50 . The age to reach the same cumulative risk as women lacking a family history at age 50 years ranged between 32.0-40.8 years.

Relative and cumulative risks of women at high risk of breast cancer associated with different clinical criteria were diverse, which may be helpful to consider when current clinical criteria are revised. According to the present results, current recommendations of starting clinical interventions 10 years earlier in high risk women, based on expert opinions, appear justified at least for the largest high risk groups. 


\section{Introduction}

In the Swedish Family-Cancer Database, $14 \%$ of women with breast cancer have a mother or sister also diagnosed with this disease [1]. Family history is a strong predictor of hereditary breast cancer, particularly when it includes cases of early onset breast cancer, bilateral breast cancer and multiple cases of breast or ovarian cancers [2]. Therefore, clinical criteria based on family history have been developed to assess the risk of breast cancer as well as to assess risk of an autosomal dominant hereditary breast and ovarian cancer gene mutation [3-7]. Genetic testing for known cancer susceptibility genes, such as BRCA1 and BRCA2, is recommended for women at high risk of breast cancer according to such criteria [5]. For example, Hampel et al. reviewed professional society guidelines, which were based on the empirical likelihood that a family history was attributable to a mutation in BRCA1/2, and developed seven criteria to identify women at increased risk for a mutation in BRCA1/2 [4]. However, the proportion of breast cancer attributable to BRCA1/2 among women at high risk according to clinical criteria has ranged from $0.7-29 \%$ (BRCA1) and from 1.5-25\% (BRCA2) for different populations [8]. Thus, women with a strong family history of breast or ovarian cancer are at high risk of breast cancer in spite of a negative genetic test for mutations in BRCA1/2 [2].

Women at high risk of breast cancer might benefit from increased surveillance and risk reducing interventions $[9,10]$. However, the recommendations for the starting age of screening in high risk women are mainly based on expert opinion [3]. Therefore, scientifically-based estimates of the risk associated with the criteria used to assess the risk of breast cancer are needed.

In the present population-based study covering the country of Sweden, the clinical criteria developed by Hampel et al. were used to classify the women in the nation-wide Swedish Family-Cancer Database. We estimated the relative risks and the cumulative incidences of breast cancer according to these criteria. The results show how many years earlier high risk 
women reach a defined risk compared to women lacking a family history, thereby providing scientific basis for antedating screening recommendations for high risk women.

\section{Materials \& Methods}

The Swedish Family-Cancer Database was created in the 1990s by linking information from the Multigeneration Register, national censuses, Swedish Cancer Registry and death notifications [11]. Data on family relationships were obtained from the Multigeneration Register, where children born in Sweden in 1932 and later are registered with their biological parents as families. The Swedish Cancer Registry is based on compulsory reports of diagnosed cases, with coverage of the cancer registration close to $100 \%$ [12]. The 2008 update of the Database includes more than 11.8 million individuals and their cancers from years 1958 to 2006 [13]. Women without identified parents were excluded from the study. The age structure of the Database (children born after 1932) implicates that the maximum age of diagnosis in the second generation is 74 years. The age of women in the first generation is not limited.

We have classified the women in the second and third generation of the Database according to seven criteria proposed by Hampel et al. which suggest a high risk of breast and ovarian cancer syndrome [4]. Women fulfilling several criteria were accounted for each criterion independently. The criteria are based on cancers in first and second degree relatives. We have defined parents and siblings as first degree relatives and grandparents, aunts, uncles and halfsiblings as second degree relatives. If a criterion called for more than one affected relative, women were classified to fulfill the criterion only if the affected relatives were blood relatives of each other. The relative risks of breast cancer were estimated as a hazard ratio (HR) using Cox regression for any of the criteria (PROC PHREG; SAS Version 9.1; SAS Institute, Cary, NC). Individuals of the second and third generation entered the risk period at birth, 
immigration, or first year of the study (1990). Censoring events were death, emigration,

100 December 31, 2006, absence at census and diagnosis of malignancy at sites other than breast.

101 Socioeconomic status, calendar period, age at first birth, number of children and region were

102 taken into account as covariates. Cumulative risks of breast cancer according to family history

103 were estimated using a stratified Cox model based on Tsiatis' method [14] (PROC PHREG;

104 SAS Version 9.1; SAS Institute, Cary, NC). The strata were defined according to the criteria.

105 For any of the criteria, we calculated the age at which the cumulative risk of women without a

106 family history at the age of 50 years was reached [15].

107

\section{Results}

109 Figure 1 shows examples for the considered familial relationships and the numbers of women

110 affected by breast cancer with a first degree relative (FDR) or second degree relative (SDR)

111 affected by breast cancer or ovarian cancer. Among the affected pairs of individuals shown in

112 Figure 1, mother-daughter pairs outnumbered sister pairs and FDRs outnumbered SDRs.

114 The hazard ratios of breast cancer in women at high risk of breast and ovarian cancer

115 syndrome according to seven criteria from Hampel et al. are shown in Table 1. The numbers

116 of women affected by breast cancer who fulfilled the criteria were variable. For example, 338

117 women with ' 1 FDR or SDR with bc diagnosed $\leq 40$ ' (criterion 1) were affected while 3

118 women were affected with ' 1 FDR or SDR with male bc and 1 FDR or SDR with bc or oc'

119 (criterion 7). The hazard ratios ranged from 1.50 ('1 FDR or SDR with male bc and 1 FDR or

120 SDR relative with bc or oc', criterion 7) to 5.99 (' $\geq 2$ FDRs or SDRs with bc or oc and 1 FDR

121 or SDR with oc', criterion 5). For all but one criterion ('1 FDR or SDR with male bc and 1

122 FDR or SDR relative with bc or oc', criterion 7), the hazard ratios were higher than for

123 women with one first degree relative affected by breast cancer (hazard ratio 1.74). However, 
124 the number of affected women with a diseased first degree relative, 5257, was over 7 times

125 higher than the number of women fulfilling criteria 1-7 (689 index cases).

127 Hazard ratios were also calculated for women younger than 50 years and older women. The 128 numbers of women affected by breast cancer before age 50 years were higher than for women

129 who were diagnosed later. Expectedly, the hazard ratios were also higher for the young

130 diagnostic group for any of the criteria; the highest hazard ratio of 8.98 was noted for criterion 1315.

133 Figure 2 represents the cumulative risk of breast cancer according to the criteria. The solid 134 curves in the bottom show the cumulative risk of women without a family history; in these 135 curves, the cumulative risk at age 50 years $(1.6 \%)$ is marked. The cumulative incidence of 136 breast cancer by age 50 years and 70 years is presented in Table 2 . By age 50 years, the 137 cumulative incidence ranged from 1.4\% ('1 FDR or SDR with male bc and 1 FDR or SDR 138 relative with bc or oc',criterion 7) to $10.3 \%$ (' $\geq 2$ FDRs or SDRs with bc or oc and 1 FDR or

139 SDR with oc', criterion 5); the percentages ranged from 7.5 to 16.5 by age 70 years. Notably,

140 from age 50 to 70 years, the cumulative incidence in women lacking a family history

141 increased from 1.6 to $6.7 \%, 4.2$-fold or 5.1 percentage units. For many of the high risk

142 women, the increases between ages 50 and 70 were relatively modest.

144 The age to reach the same cumulative risk of breast cancer as women lacking a family history 145 at the age 50 years $(1.6 \%)$ and age 40 years $(0.33 \%)$ is shown in Table 3 . The difference 'Age 146 difference' to reach the risk of $1.6 \%$ due to the family history was highest for women with ' $\geq$

1472 FDRs or SDRs with bc or oc and 1 FDR or SDR with oc', criterion 5, 18.0 years) and

148 lowest for women with ' 1 FDR or SDR affected by bc $\leq 40$ years', criterion 1, 9.2 years). The 149 age difference to reach the risk of $0.33 \%$ was between 7.2 years (' 1 FDR or SDR affected by 
bc $\leq 40$ years', criterion $1, ' \geq 2$ FDRs or SDRs with bc if one is diagnosed $\leq 50$ y or

151 bilateral', criterion 3) and 10.0 years (' 1 FDR or SDR with bc diagnosed $\leq 50$ y or bilateral

152 and 1 FDR or SDR with oc', criterion 4). However, for criterion 5 - 7, the number of cases

153 was too small for the analysis of the age to reach the risk of $0.33 \%$.

The considered criteria were overlapping. Table 4 shows the numbers of women that fulfilled two criteria. For example, 13 of 14 women with ' $\geq 2$ FDRs or SDRs with bc or oc and 1 FDR or SDR with oc' (criterion 5) also fulfilled the criterion '1 FDR or SDR with bc diagnosed $\leq$ 50 y or bilateral and 1 FDR or SDR with oc' (criterion 4).

\section{Discussion}

161 The novel findings of the present study included a nation-wide definition of age-related relative and cumulative risks for women at high risk of breast cancer, which included 689 index cases. The largest high risk groups reached the cumulative risk of $1.6 \%$, which was the cumulative risk of sporadic cases at the age of 50 years, some 10 years before the sporadic group. Another novel finding of also major practical importance was the description of

166 familial breast cancers outside the high risk families. These included 5263 patients with a FDR with breast cancer and over 1400 patients with SDR with breast cancer or FDR with ovarian cancer. The number of potentially detectable cases in the latter groups far exceeded the cases in the high risk groups, as will be discussed below. Familial breast cancer cases, not

170 belonging to the high risk groups, reached the cumulative risk of $1.6 \%$ about 5 years before 171 sporadic cases.

173 The present study includes the whole Swedish population up to age 74 years and their parents, 174 whose family relationships and cancer data originated from reliable and practically complete 175 registered sources. Although the study included the whole Swedish population, the number of 
women affected by breast cancer fulfilling any of the criteria was small. This was expected as

177 the criteria aim at identifying women at risk of hereditary breast ovarian syndrome, which is rare [16]. Furthermore, the structure of the Database implies that the identification of or later, i.e., three generations were to be identified where the youngest one aged $\sim 50$ years or

181 less. The relatively small numbers of women diagnosed with breast cancer with a SDR

182 affected is in part explained by the young age of the third generation. This might also be a reason for the relatively low proportion of breast cancers over 50 years in women fulfilling a criterion. Furthermore, women who fulfill the criteria are probably younger than the average women in the second generation, which might lead to an overestimation of the risks because

186 familial cancer is associated with an earlier age of onset. As a further technical point, the 187 present calculations were based on the register-based definition of the family history which did not consider the time of family member's diagnosis. In clinical counseling and screening situations, women enter the familial group only from the diagnosis date of the affected relative(s). We have carried out some analyses using the latter definition with practically

191 unchanged results. However, a major problem with the latter definition is a reduction of case

192 numbers because the familial group only includes cases after the relative's diagnosis.

193 Identical results following both types of calculations for familial risk in groups with large

194 enough case numbers reassure that the present results should be applicable to the clinical and 195 screening situations.

197 The numbers of index cases and the risks that we found for the different high risk criteria 198 were diverse, ranging from three cases and no increased risk in criterion 7 with male breast 199 cancers to 14 cases and a hazard ratio of 5.99 in criterion 5 with multiple affected family 200 members. Nevertheless, it is known that male breast cancer is a strong predictor of hereditary 201 breast ovarian cancer syndrome. The finding that the risk was not increased in criterion 7 was 
probably due to a lack of power to prove the association for this criterion, the number of 203 women fulfilling this criterion being small. The largest groups, criteria 1 and 3, included early onset breast cancers with intermediary hazard ratios. The cumulative incidence of breast cancer by age 50 was $1.6 \%$ in women lacking a family history while that cumulative incidence was reached between 9 years $(95 \%$ CI $8 \mathrm{y}-11 \mathrm{y}$, criterion 1$)$ and 18 years $(95 \%$ CI $8 \mathrm{y}-20 \mathrm{y}$, criterion 5) earlier in women belonging to any of the high risk groups (except criterion 7). The diversity of the risks depending on the criterion is likely to be explained in part by different proportions of BRCA1/2 mutation carriers in women fulfilling the criteria [17]. Empirically, mutation detection rates are highest in the groups where we found the highest risks $[17,18]$ and the characteristics of these groups would also yield increased 212 predictions for mutation positivity using the BRCAPRO and BOADICEA programs [19-22]. 213 For women carrying mutations in BRCA1/2, the estimated cumulative risk of breast cancer by 214 the age of 50 years range from 28-39\% (BRCA1) and 16-23\% (BRCA2), respectively; by age 70, the corresponding risk estimates are between 46-65\% and between 45-56\% [23-26]. We have found cumulative breast cancer risks between 1-10\% at the age of 50 and between 7-

$217 \quad 17 \%$ at age 70 . These proportions show that the majority of breast cancers even in the high 218 risk groups are not associated with mutations in BRCA1/2, in agreement with mutation testing 219 results $[17,18]$. A major weakness of our study is that we lack data on the mutation status of 220 the subjects and we thus lack the possibility of risk estimation for women belonging to the 221 high risk groups but who test negative. The risk of women outside mutation positive families 222 should, at a minimum, exceed the familial risks of women with one affected FDR diagnosed 223 with breast cancer, not fulfilling the high risk criteria (i.e., hazard ratio 1.74) [2]. Mutation negative women with a known familial mutation should be considered as average risk. [27]

226 Considering that 5257 index women with one FDR diagnosed with breast cancer and not 227 fulfilling the high risk criteria showed an excess risk of 0.74 (1.74-1.00), the number of cases 
due to family history was about $2240(5257 \mathrm{x}(0.74 / 1.74))$, which was much higher than the 12 (ie, extra risk of $4.99 \times 14 / 5.99$, criterion 5) to 209 (1.63 x 338/2.63, criterion 1$)$ extra number of cases among the high risk index cases. As these women reached the cumulative risk of $1.6 \% 4.8$ years before the women lacking a family history, any screening efforts for these women should be started at 45 years if the others are offered screening at 50 years.

It has been shown that women with an increased risk of breast cancer might benefit from an intensified surveillance and risk reducing interventions, which includes an earlier start of mammography screening, MRI screening, chemoprevention and risk reducing surgery $[9,10,28,29]$. The starting age of mammography screening for women at increased risk is not well established. The American Cancer Society recommends average-risk women to start with mammography screening at the age of 40 years [30]. Women at increased risk of breast cancer, which includes women with a relative affected by breast cancer before 50 years, with two or more relatives affected by breast or ovarian cancer, with male breast cancer and with a relative affected by two independent breast cancers, are recommended to start 10 years earlier

243 than average risk women, or 5-10 years earlier than the youngest patient in the family [3]. The 244 above recommendations are mainly based on expert opinion, with support from the assessment of breast cancer risk with statistical models or epidemiological studies [6,31-33]. The National Center for Clinical Excellence in the UK recommends for at-risk women annual mammography screening beginning at the age of 40 years, which is 10 years earlier than the

248 recommended starting age in the UK for the general population [7]. For the surveillance 249 between 30 and 40 years by mammography screening for women with BRCA1/2 mutations or 250 at equivalent high risk, individual strategies are suggested [7].

251 There is good evidence that the efficacy of mammography screening in average risk women is 252 lower in women aged 40-49 years than in those aged 50-69 years [34,35]. No evidence has 253 been found for the efficacy of screening under the age 40 years. Furthermore, a poor 
254 performance of mammography screening in BRCA1/2 carriers has been reported [35].

255 Nevertheless, women with increased risk might benefit of earlier mammography screening 256 but a mortality reduction has not yet been shown [29]. Therefore, the American Cancer 257 Society recommends MRI screening as an adjunct to mammography screening for women 258 with an estimated $20-25 \%$ or greater lifetime risk of breast cancer [36]. Annual MRI

259 screening between 30 and 40 years is recommended for women with an estimated breast 260 cancer risk $>8 \%$ in this period by the National Center for Clinical Excellence [37]. Our risk 261 estimates are well below these risks for any of the considered criteria. Thus, according to the 262 above recommendations, our results indicate that MRI screening is not eligible solely on the 263 basis of these clinical criteria. Our present data show the age differences for the cumulative 264 risks for women at various risk levels estimated with a large population-based data set, and 265 thus provide some justification for the timing of interventions. However, they cannot suggest 266 the methods of intervention nor predict their success.

268 Another application of the present data may be in the adjuvant therapy of breast cancer. A 269 combined analysis of 6 studies has shown a reduction of $38 \%$ of the breast cancer incidence 270 by tamoxifen treatment [38]. Tamoxifen has, however, serious side-effects. Gail et al. have 271 shown that the risk-benefit ratio is dependent on the age and the risk to develop breast cancer 272 within the period of tamoxifen use [39]. They have demonstrated that tamoxifen is most 273 beneficial for younger women with an increased risk of breast cancer. Thus, our risk 274 estimations might support the decision for or against tamoxifen treatment as a risk reducing 275 intervention.

277 In conclusion, the relative and cumulative risk of women at high risk of breast cancer 278 associated with different clinical criteria is diverse. With the discussed limitations, the present 279 data may help to evaluate and to improve current clinical criteria for the assessment of breast 
280 cancer risk. They offer scientific bases for clinical counseling and screening activities targeted 281 at high risk patients; these should commence some 10 years before sporadic patients. For 282 familial patients outside the high risk groups the activities should commence 5 years earlier. 283

\section{ACKNOWLEDGEMENTS}

286 This work was supported by Deutsche Krebshilfe, The Swedish Council for Working Life and 287 Social Research. The Family-Cancer Database was created by linking registers maintained at 288 Statistics Sweden and the Swedish Cancer Registry. 


\section{References}

291 1. Hemminki K, Sundquist J, Bermejo JL (2008) How common is familial cancer? Ann Oncol 19:163-167

2. Evans DG, Lalloo F (2002) Risk assessment and management of high risk familial breast cancer. J Med Genet 39:865-871

3. Smith RA, Saslow D, Sawyer KA, Burke W, Costanza ME, Evans WP, 3rd, Foster RS, Jr., Hendrick E, Eyre HJ, Sener S (2003) American Cancer Society guidelines for breast cancer screening: update 2003. CA Cancer J Clin 53:141-169

4. Hampel H, Sweet K, Westman JA, Offit K, Eng C (2004) Referral for cancer genetics consultation: a review and compilation of risk assessment criteria. J Med Genet 41:8191

5. U.S. Preventive Services Task Force (2005) Genetic risk assessment and BRCA mutation testing for breast and ovarian cancer susceptibility: recommendation statement. Ann Intern Med 143:355-361

6. Claus EB, Risch N, Thompson WD (1994) Autosomal dominant inheritance of earlyonset breast cancer. Implications for risk prediction. Cancer 73:643-651

7. McIntosh A, Shaw C, Evans G, Turnbull N, Bahar N, Barclay M, Easton DF, Emery J, Gray J, Halpin J, Hopwood P, McKay J, Sheppard C, Sibbering M, Watson W, Wailoo A, Hutchinson A (2004) Clinical Guidelines and Evidence Review for The

311 8. Fackenthal JD, Olopade OI (2007) Breast cancer risk associated with BRCA1 and BRCA2 in diverse populations. Nat Rev Cancer 7:937-948

313 9. Moller P, Reis MM, Evans G, Vasen H, Haites N, Anderson E, Steel CM, Apold J, Lalloo F, Maehle L, Preece P, Gregory H, Heimdal K (1999) Efficacy of early 
diagnosis and treatment in women with a family history of breast cancer. European Familial Breast Cancer Collaborative Group. Dis Markers 15:179-186

10. Brekelmans CT, Seynaeve C, Bartels CC, Tilanus-Linthorst MM, Meijers-Heijboer EJ, Crepin CM, van Geel AA, Menke M, Verhoog LC, van den Ouweland A, Obdeijn IM, Klijn JG (2001) Effectiveness of breast cancer surveillance in BRCA1/2 gene mutation carriers and women with high familial risk. J Clin Oncol 19:924-930

11. Hemminki K, Li X, Plna K, Granstrom C, Vaittinen P (2001) The nation-wide Swedish family-cancer database--updated structure and familial rates. Acta Oncol 40:772-777

12. Centre for Epidemiology (2007) Cancer incidence in Sweden 2005. The National Board of Health and Welfare, Stockholm

13. Hemminki K, Granström C, Sundquist J, Lorenzo Bermejo J (2006) The updated Swedish family-cancer database used to assess familial risks of prostate cancer during rapidly increasing incidence Heredit Cancer in Clin Pract 4:186-192

14. Tsiatis A (1981) A Large Sample Study of the Estimates for the Integrated Hazard Function in Cox's Regression Model for Survival Data. Annals of Statistics 9:93-108

15. Lai TL, Su Z (2006) Confidence intervals for survival quantiles in the Cox regression model. Lifetime Data Anal 12:407-419

16. Turnbull C, Rahman N (2008) Genetic predisposition to breast cancer: past, present, and future. Annu Rev Genomics Hum Genet 9:321-345

17. German Consortium for Hereditary Breast and Ovarian Cancer (2002) Comprehensive analysis of 989 patients with breast or ovarian cancer provides BRCA1 and BRCA2 mutation profiles and frequencies for the German population. Int J Cancer 97:472-480 
of individuals with germline mutations in BRCA1 and BRCA2: analysis of 10,000 individuals. J Clin Oncol 20:1480-1490

19. Parmigiani G, Berry D, Aguilar O (1998) Determining carrier probabilities for breast cancer-susceptibility genes BRCA1 and BRCA2. Am J Hum Genet 62:145-158

20. Antoniou AC, Pharoah PD, McMullan G, Day NE, Stratton MR, Peto J, Ponder BJ, Easton DF (2002) A comprehensive model for familial breast cancer incorporating BRCA1, BRCA2 and other genes. Br J Cancer 86:76-83

21. Berry DA, Iversen ES, Jr., Gudbjartsson DF, Hiller EH, Garber JE, Peshkin BN,

22. Antoniou AC, Pharoah PP, Smith P, Easton DF (2004) The BOADICEA model of genetic susceptibility to breast and ovarian cancer. Br J Cancer 91:1580-1590

23. Antoniou A, Pharoah PD, Narod S, Risch HA, Eyfjord JE, Hopper JL, Loman N, Olsson H, Johannsson O, Borg A, Pasini B, Radice P, Manoukian S, Eccles DM, Tang N, Olah E, Anton-Culver H, Warner E, Lubinski J, Gronwald J, Gorski B, Tulinius H, Thorlacius S, Eerola H, Nevanlinna H, Syrjakoski K, Kallioniemi OP, Thompson D, Evans C, Peto J, Lalloo F, Evans DG, Easton DF (2003) Average risks of breast and ovarian cancer associated with BRCA1 or BRCA2 mutations detected in case Series unselected for family history: a combined analysis of 22 studies. Am J Hum Genet $72: 1117-1130$

24. Chen S, Iversen ES, Friebel T, Finkelstein D, Weber BL, Eisen A, Peterson LE, Schildkraut JM, Isaacs C, Peshkin BN, Corio C, Leondaridis L, Tomlinson G, Dutson D, Kerber R, Amos CI, Strong LC, Berry DA, Euhus DM, Parmigiani G (2006) 
Characterization of BRCA1 and BRCA2 mutations in a large United States sample. J Clin Oncol 24:863-871

25. Chen S, Parmigiani G (2007) Meta-analysis of BRCA1 and BRCA2 penetrance. J Clin Oncol 25:1329-1333

26. Anglian Breast Cancer Study Group (2000) Prevalence and penetrance of BRCA1 and BRCA2 mutations in a population-based series of breast cancer cases. . Br J Cancer 83:1301-1308

27. Berliner JL, Fay AM (2007) Risk assessment and genetic counseling for hereditary breast and ovarian cancer: recommendations of the National Society of Genetic Counselors. J Genet Couns 16:241-260

28. Fisher B, Costantino JP, Wickerham DL, Cecchini RS, Cronin WM, Robidoux A, Bevers TB, Kavanah MT, Atkins JN, Margolese RG, Runowicz CD, James JM, Ford

29. Eccles DM (2004) Hereditary cancer: guidelines in clinical practice. Breast and ovarian cancer genetics. Ann Oncol 15 Suppl 4:iv133-138

30. Smith RA, Cokkinides V, Eyre HJ (2007) Cancer screening in the United States, 2007: a review of current guidelines, practices, and prospects. CA Cancer J Clin 57:90-104

31. Gail MH, Brinton LA, Byar DP, Corle DK, Green SB, Schairer C, Mulvihill JJ (1989) Projecting individualized probabilities of developing breast cancer for white females who are being examined annually. J Natl Cancer Inst 81:1879-1886

32. Tyrer J, Duffy SW, Cuzick J (2004) A breast cancer prediction model incorporating familial and personal risk factors. Stat Med 23:1111-1130

33. Decarli A, Calza S, Masala G, Specchia C, Palli D, Gail MH (2006) Gail model for 
Florence-European Prospective Investigation Into Cancer and Nutrition cohort. J Natl Cancer Inst 98:1686-1693

34. Moss SM, Cuckle H, Evans A, Johns L, Waller M, Bobrow L (2006) Effect of mammographic screening from age 40 years on breast cancer mortality at 10 years' follow-up: a randomised controlled trial. Lancet 368:2053-2060

35. IARC (2002) Breast cancer screening. IARC Press, Lyon

36. Saslow D, Boetes C, Burke W, Harms S, Leach MO, Lehman CD, Morris E, Pisano E, Schnall M, Sener S, Smith RA, Warner E, Yaffe M, Andrews KS, Russell CA (2007) American Cancer Society guidelines for breast screening with MRI as an adjunct to mammography. CA Cancer J Clin 57:75-89

37. National Collaborating Centre for PrimaryCare (2006) The classifacation and care of women at risk of familial breast cancer in primary, secondary and tertiary care Update. http://www.nice.org.uk/nicemedia/pdf/CG41fullguidance.pdf. Accessed 6 May 2009

38. Cuzick J, Powles T, Veronesi U, Forbes J, Edwards R, Ashley S, Boyle P (2003) Overview of the main outcomes in breast-cancer prevention trials. Lancet 361:296300

39. Gail MH, Costantino JP, Bryant J, Croyle R, Freedman L, Helzlsouer K, Vogel V (1999) Weighing the risks and benefits of tamoxifen treatment for preventing breast cancer. J Natl Cancer Inst 91:1829-1846 
Figure 1 Examples of the considered familial relationships and numbers of women affected by breast cancer with a first or second degree relative affected by breast or ovarian cancer. Squares are men, circles are women; filled circles are affected women

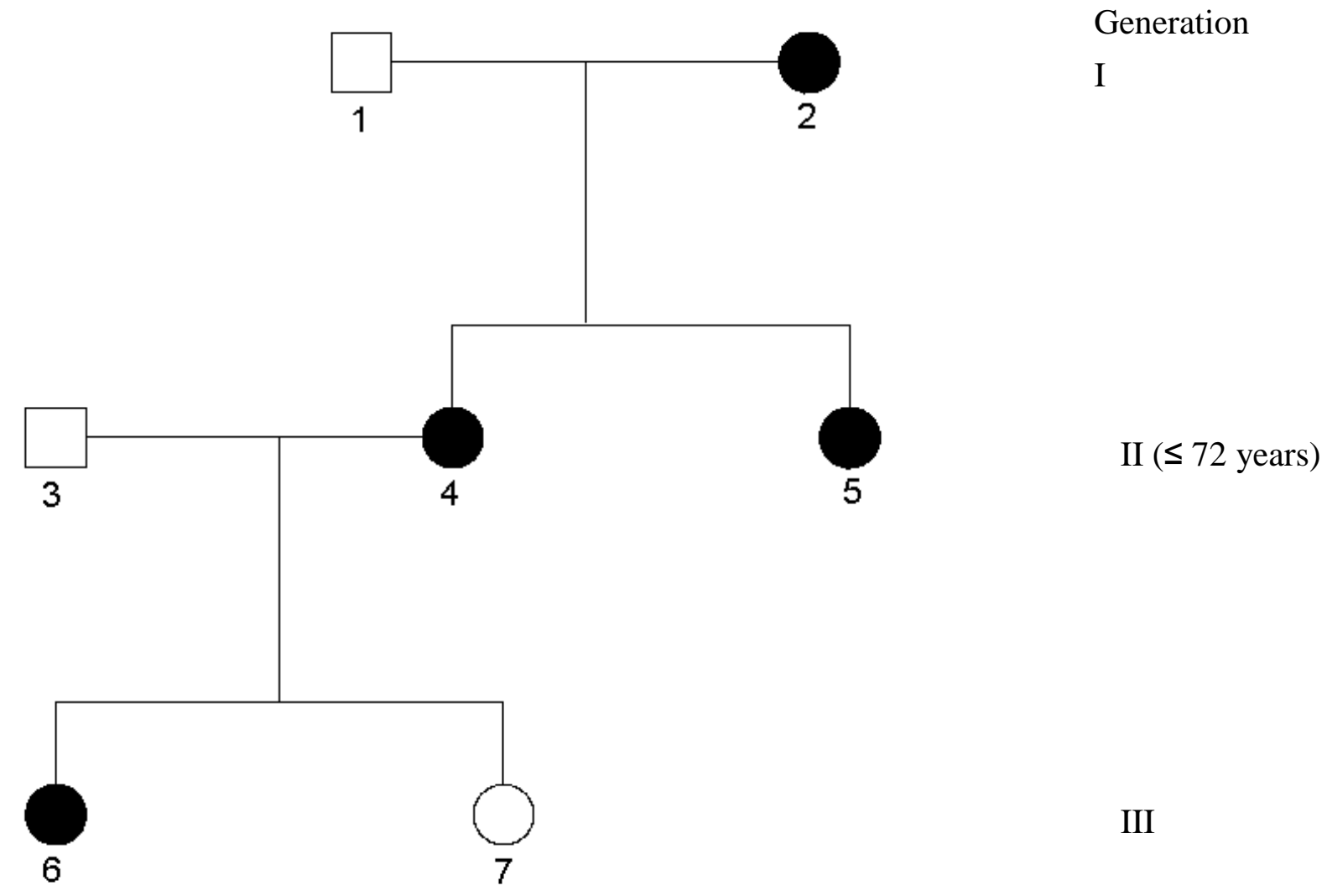

Cancer site of relative

\begin{tabular}{lllrr} 
& Familial relationship & Example & Breast & Ovary \\
\hline \multirow{2}{*}{ First degree relatives } & mother - daughter & $2-4$ & 3938 & 699 \\
& sister - sister & $4-5$ & 2160 & 212 \\
Second degree relatives & grandmother - granddaughter & $2-6$ & 399 & 80 \\
& aunt - niece & $5-6$ & 211 & 44 \\
& half-sister - half-sister & not shown & 160 & 18 \\
\hline
\end{tabular}


Table 1 Hazard ratios of breast cancer for women that fulfilled high risk criteria for breast and ovarian cancer syndrome by age at diagnosis

\begin{tabular}{|c|c|c|c|c|c|c|c|c|c|c|c|c|c|c|c|c|}
\hline \multirow[b]{3}{*}{1} & \multirow{3}{*}{$\begin{array}{l}\text { Criterion } \\
1 \mathrm{FDR}^{\mathrm{a}} \text { or } \mathrm{SDR}^{\mathrm{b}} \text { with } \mathrm{bc}^{\mathrm{c}} \text { diagnosed } \leq 40 \mathrm{y}\end{array}$} & \multirow{3}{*}{$\begin{array}{l}\mathrm{N} \\
338\end{array}$} & \multirow{3}{*}{$\begin{array}{r}\mathrm{HR} \\
2.63\end{array}$} & \multicolumn{3}{|c|}{ Any age } & \multicolumn{5}{|c|}{$<50$ years } & \multicolumn{5}{|c|}{$\geq 50$ years } \\
\hline & & & & \multicolumn{2}{|c|}{$95 \% \mathrm{CI}$} & \multirow{2}{*}{$\begin{array}{c}\mathrm{P} \\
<0.0001\end{array}$} & \multirow{2}{*}{$\begin{array}{r}\mathrm{N} \\
229\end{array}$} & \multirow{2}{*}{$\begin{array}{r}\text { HR } \\
3.24\end{array}$} & \multicolumn{2}{|c|}{$95 \% \mathrm{CI}$} & \multirow{2}{*}{$\begin{array}{c}\mathrm{P} \\
<0.0001\end{array}$} & \multirow{2}{*}{$\begin{array}{c}\text { No. } \\
109\end{array}$} & \multirow{2}{*}{$\begin{array}{l}\mathrm{HR} \\
1.90\end{array}$} & \multicolumn{2}{|c|}{$95 \% \mathrm{CI}$} & \multirow{2}{*}{$\begin{array}{c}\mathrm{P} \\
<0.0001\end{array}$} \\
\hline & & & & 2.36 & 2.93 & & & & 2.84 & 3.69 & & & & 1.57 & 2.29 & \\
\hline 2 & 1 FDR or SDR with both bc and oc ${ }^{\mathrm{d}}$ & 88 & 2.92 & 2.37 & 3.60 & $<0.0001$ & 52 & 4.09 & 3.11 & 5.37 & $<0.0001$ & 36 & 2.07 & 1.49 & 2.87 & $<0.0001$ \\
\hline 3 & $\begin{array}{l}\geq 2 \text { FDRs or SDRs with bc } \\
\text { if one is diagnosed } \leq 50 \text { y or bilateral }\end{array}$ & 289 & 3.27 & 2.91 & 3.67 & $<0.0001$ & 158 & 3.87 & 3.31 & 4.26 & $<0.0001$ & 131 & 2.74 & 2.31 & 3.26 & $<0.0001$ \\
\hline 4 & $\begin{array}{l}1 \text { FDR or SDR with bc } \\
\text { diagnosed } \leq 50 \text { y or bilateral and } \\
1 \text { FDR or SDR with oc }\end{array}$ & 66 & 4.25 & 3.34 & 5.41 & $<0.0001$ & 49 & 6.42 & 4.85 & 8.49 & $<0.0001$ & 17 & 2.16 & 1.34 & 3.47 & 0.002 \\
\hline 5 & $\begin{array}{l}\geq 2 \text { FDRs or SDRs with bc or oc and } \\
1 \text { FDR or SDR with oc }\end{array}$ & 14 & 5.99 & 3.55 & 10.10 & $<0.0001$ & 12 & 8.98 & 5.10 & 15.81 & $<0.0001$ & 2 & 1.98 & 0.50 & 7.91 & 0.33 \\
\hline 6 & $\geq 2$ FDRs or SDRs with oc & 23 & 3.45 & 2.30 & 5.19 & $<0.0001$ & 19 & 5.92 & 3.78 & 9.27 & $<0.0001$ & 4 & 1.16 & 0.43 & 3.09 & 0.77 \\
\hline 7 & $\begin{array}{l}1 \text { FDR or SDR with male bc and } \\
1 \text { FDR or SDR with bc or oc }\end{array}$ & 3 & 1.50 & 0.49 & 4.65 & 0.48 & 1 & 1.00 & 0.14 & 7.11 & 0.99 & 2 & 2.06 & 0.53 & 8.04 & 0.30 \\
\hline & $1 \mathrm{bc}$ in FDR, none of criteria $1-7$ & 5257 & 1.74 & 1.69 & 1.79 & $<0.0001$ & 1906 & 1.84 & 1.76 & 1.94 & $<0.0001$ & 3351 & 1.68 & 1.62 & 1.74 & $<0.0001$ \\
\hline & $1 \mathrm{bc}$ in SDR, none of criteria $1-7$ & 612 & 1.46 & 1.34 & 1.58 & $<0.0001$ & 527 & 1.41 & 1.29 & 1.54 & $<0.0001$ & 85 & 1.73 & 1.39 & 2.13 & $<0.0001$ \\
\hline & $1 \mathrm{oc}$ in FDR, none of criteria $1-7$ & 817 & 1.36 & 1.27 & 1.45 & $<0.0001$ & 323 & 1.60 & 1.43 & 1.79 & $<0.0001$ & 494 & 1.23 & 1.13 & 1.35 & $<0.0001$ \\
\hline & $1 \mathrm{oc}$ in SDR, none of criteria $1-7$ & 101 & 1.19 & 0.97 & 1.44 & 0.09 & 93 & 1.21 & 0.98 & 1.48 & 0.07 & 8 & 0.98 & 0.49 & 1.95 & 0.94 \\
\hline
\end{tabular}


Figure 2 Cumulative risk of breast cancer for women that fulfilled high risk criteria for breast and ovarian cancer syndrome
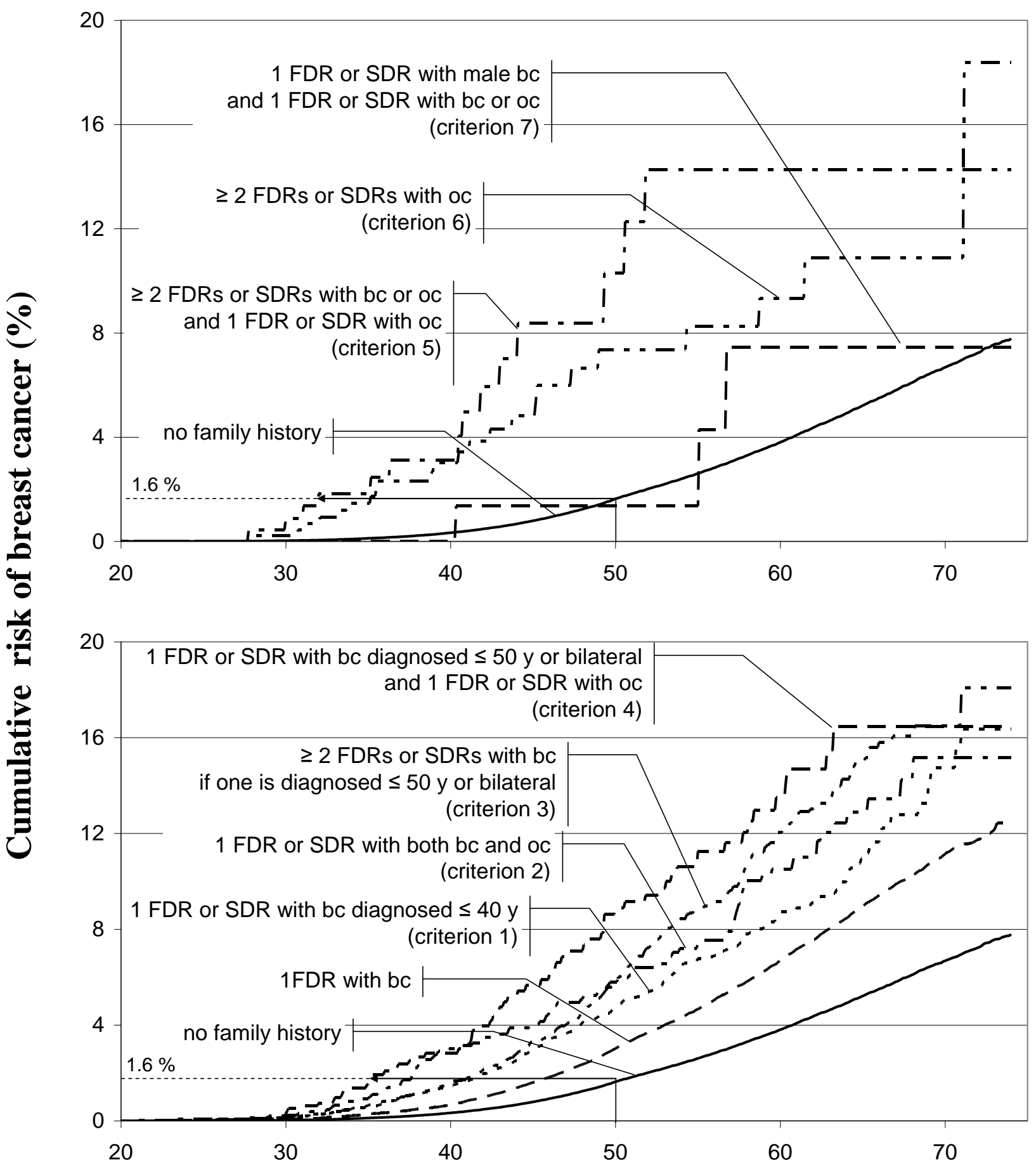

Age (years) 
Table 2 Cumulative risk of breast cancer by age 50 and 70 years

\begin{tabular}{|c|c|c|c|c|c|c|c|}
\hline \multirow{2}{*}{\multicolumn{2}{|c|}{ Criterion }} & \multicolumn{3}{|c|}{50 years } & \multicolumn{3}{|c|}{70 years } \\
\hline & & $\mathrm{CR}(\%)$ & $95 \%$ & $6 \mathrm{CI}$ & CR $(\%)$ & $95 \%$ & CI \\
\hline 1 & $1 \mathrm{FDR}^{\mathrm{a}}$ or $\mathrm{SDR}^{\mathrm{b}}$ with $\mathrm{bc}^{\mathrm{c}}$ diagnosed $\leq 40 \mathrm{y}$ & 4.7 & 4.1 & 5.4 & 14.7 & 12.0 & 17.5 \\
\hline 2 & 1 FDR or SDR with both bc and oc ${ }^{\mathrm{d}}$ & 5.8 & 4.2 & 7.4 & 15.2 & 11.3 & 19.0 \\
\hline 3 & $\begin{array}{l}\geq 2 \text { FDRs or SDRs with bc } \\
\text { if one is diagnosed } \leq 50 \text { y or bilateral }\end{array}$ & 5.8 & 4.9 & 6.8 & 16.5 & 14.2 & 18.7 \\
\hline 4 & $\begin{array}{l}1 \text { FDR or SDR with bc } \\
\text { diagnosed } \leq 50 \text { y or bilateral and } \\
1 \text { FDR or SDR with oc }\end{array}$ & 8.9 & 6.4 & 11.4 & 16.5 & 12.0 & 20.9 \\
\hline 5 & $\begin{array}{l}\geq 2 \text { FDRs or SDRs with bc or oc and } \\
1 \text { FDR or SDR with oc }\end{array}$ & 10.3 & 4.0 & 16.5 & 14.3 & 6.2 & 22.3 \\
\hline 6 & $\geq 2$ FDRs or SDRs with oc & 7.4 & 3.9 & 10.8 & 10.9 & 5.7 & 16.1 \\
\hline 7 & $\begin{array}{l}1 \text { FDR or SDR with male bc and } \\
1 \text { FDR or SDR with bc or oc }\end{array}$ & 1.4 & 0.0 & 4.0 & 7.5 & 0.0 & 16.0 \\
\hline & $1 \mathrm{bc}$ in FDR, none of criteria $1-7$ & 3.0 & 2.9 & 3.2 & 11.1 & 10.7 & 11.6 \\
\hline & $1 \mathrm{bc}$ in SDR, none of criteria $1-7$ & 2.1 & 1.8 & 2.4 & 10.1 & 7.8 & 12.4 \\
\hline & $1 \mathrm{oc}$ in FDR, none of criteria $1-7$ & 2.7 & 2.4 & 3.0 & 8.8 & 8.0 & 9.5 \\
\hline & 1 oc in SDR, none of criteria $1-7$ & 2.3 & 1.6 & 3.0 & 8.3 & 3.1 & 13.5 \\
\hline & No family history & 1.6 & 1.6 & 1.7 & 6.7 & 6.5 & 6.9 \\
\hline
\end{tabular}

${ }^{a}$ first degree relative (parent, sibling)

${ }^{\mathrm{b}}$ second degree relative (grandparent, aunt/uncle, half-sibling)

${ }^{\mathrm{c}}$ breast cancer

${ }^{\mathrm{d}}$ ovarian cancer 
Table 3 Age at which women that fulfilled high risk criteria for breast and ovarian cancer syndrome reach the cumulative risk of women lacking a

family history at age 50 years and 40 years.

\begin{tabular}{|c|c|c|c|c|c|c|c|c|c|c|c|}
\hline \multirow{2}{*}{\multicolumn{2}{|c|}{ Criterion }} & \multicolumn{5}{|c|}{50 years } & \multicolumn{5}{|c|}{40 years } \\
\hline & & \multirow{2}{*}{$\begin{array}{l}\mathrm{N}^{\mathrm{e}} \\
110\end{array}$} & \multirow{2}{*}{$\begin{array}{c}\operatorname{Age}^{\mathrm{f}} \\
40.8\end{array}$} & \multicolumn{2}{|c|}{$95 \% \mathrm{CI}$} & \multirow{2}{*}{$\begin{array}{l}\begin{array}{l}\text { Age } \\
\text { difference }\end{array} \\
9.2\end{array}$} & \multirow{2}{*}{$\begin{array}{l}\mathrm{N}^{\mathrm{e}} \\
27\end{array}$} & \multirow{2}{*}{$\begin{array}{r}\mathrm{Age}^{\mathrm{g}} \\
32.8\end{array}$} & \multicolumn{2}{|c|}{$95 \% \mathrm{CI}$} & \multirow{2}{*}{$\begin{array}{l}\begin{array}{l}\text { Age } \\
\text { difference }\end{array} \\
\qquad 7.3\end{array}$} \\
\hline 1 & $1 \mathrm{FDR}^{\mathrm{a}}$ or $\mathrm{SDR}^{\mathrm{b}}$ with $\mathrm{bc}^{\mathrm{c}}$ diagnosed $\leq 40 \mathrm{y}$ & & & 39.4 & 42.3 & & & & 31.4 & 33.8 & \\
\hline 2 & 1 FDR or SDR with both bc and oc ${ }^{\mathrm{d}}$ & 18 & 37.0 & 35.3 & 38.8 & 13.0 & 4 & 31.4 & 28.7 & 34.3 & 8.6 \\
\hline 3 & $\begin{array}{l}\geq 2 \text { FDRs or SDRs with bc } \\
\text { if one is diagnosed } \leq 50 \text { y or bilateral }\end{array}$ & 66 & 40.4 & 38.8 & 41.9 & 9.6 & 17 & 32.8 & 31.4 & 34.1 & 7.3 \\
\hline 4 & $\begin{array}{l}1 \text { FDR or SDR with bc } \\
\text { diagnosed } \leq 50 \text { y or bilateral and } \\
1 \text { FDR or SDR with oc }\end{array}$ & 14 & 35.1 & 33.4 & 38.4 & 14.9 & 4 & 30.0 & 29.0 & 32.9 & 10.0 \\
\hline 5 & $\begin{array}{l}\geq 2 \text { FDRs or SDRs with bc or oc and } \\
1 \text { FDR or SDR with oc }\end{array}$ & 4 & 32.0 & 30.0 & 41.8 & 18.0 & & & & & \\
\hline 6 & $\geq 2$ FDRs or SDRs with oc & 6 & 35.4 & 32.1 & 41.1 & 14.6 & & & & & \\
\hline \multicolumn{12}{|c|}{$\begin{array}{l}71 \text { FDR or SDR with male bc and } \\
1 \text { FDR or SDR with bc or oc }\end{array}$} \\
\hline & $1 \mathrm{bc}$ in FDR, none of criteria $1-7$ & 952 & 45.2 & 44.8 & 45.7 & 4.8 & 153 & 35.9 & 35.3 & 36.8 & 4.1 \\
\hline & $1 \mathrm{bc}$ in SDR, none of criteria $1-7$ & 512 & 47.3 & 46.5 & 48.5 & 2.7 & 246 & 38.2 & 37.5 & 38.6 & 1.8 \\
\hline & 1 oc in FDR, none of criteria $1-7$ & 172 & 45.4 & 44.5 & 46.8 & 4.6 & 22 & 33.3 & 31.7 & 37.1 & 6.7 \\
\hline & 1 oc in SDR, none of criteria $1-7$ & 84 & 48.5 & 47.3 & 51.3 & 1.5 & 47 & 39.2 & 38.0 & 41.1 & 0.8 \\
\hline
\end{tabular}

${ }^{a}$ first degree relative (parent, sibling)

${ }^{\mathrm{b}}$ second degree relative (grandparent, aunt/uncle, half-sibling)

${ }^{\mathrm{c}}$ breast cancer

d ovarian cancer

${ }^{\mathrm{e}} \mathrm{Number}$ of cases until 'Age'

${ }^{\mathrm{f}}$ Age to reach the same risk as women lacking a family history at age 50 years

${ }^{\mathrm{g}}$ Age to reach the same risk as women lacking a family history at age 40 years 
Table 3 Number of women that fulfilled two criteria

\begin{tabular}{|c|c|c|c|c|c|c|c|c|}
\hline \multirow{2}{*}{\multicolumn{2}{|c|}{ Criterion }} & \multicolumn{7}{|c|}{ Women that fulfilled two criteria } \\
\hline & & 1 & 2 & 3 & 4 & 5 & 6 & 7 \\
\hline 1 & $\begin{array}{l}1 \mathrm{FDR}^{\mathrm{a}} \text { or } \mathrm{SDR}^{\mathrm{b}} \text { with } \mathrm{bc}^{\mathrm{c}} \text { diagnosed } \\
\leq 40 \mathrm{y}\end{array}$ & 338 & & & & & & \\
\hline 2 & 1 FDR or SDR with both bc and oc ${ }^{d}$ & 14 & 88 & & & & & \\
\hline 3 & $\begin{array}{l}\geq 2 \text { FDRs or SDRs with bc } \\
\text { if one is diagnosed } \leq 50 \mathrm{y} \text { or bilateral }\end{array}$ & 71 & 11 & 289 & & & & \\
\hline 4 & $\begin{array}{l}1 \text { FDR or SDR with bc } \\
\text { diagnosed } \leq 50 \text { y or bilateral and } \\
1 \text { FDR or SDR with oc }\end{array}$ & 14 & 6 & 14 & 66 & & & \\
\hline 5 & $\begin{array}{l}\geq 2 \text { FDRs or SDRs with bc or oc and } \\
1 \text { FDR or SDR with oc }\end{array}$ & 5 & 2 & 11 & 13 & 14 & & \\
\hline 6 & $\geq 2$ FDRs or SDRs with oc & 0 & 0 & 0 & 2 & 3 & 23 & \\
\hline 7 & $\begin{array}{l}1 \text { FDR or SDR with male bc and } \\
1 \text { FDR or SDR with bc or oc }\end{array}$ & 0 & 0 & 0 & 0 & 0 & 0 & 3 \\
\hline
\end{tabular}

